\title{
La vida cotidiana en las escuelas secundarias: contexto escenario y actores
}

\author{
Ricardo Fuentes Reza \\ Profesor investigador \\ Centro de Investigación y Docencia
}

\section{Resumen}

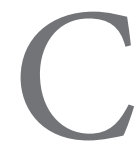

on este trabajo se pretende destacar la manera en que el contexto adquiere una alta significación para la vida interna de las escuelas. Lo que sucede fuera de los establecimientos es tanto o más importante para la vida institucional que lo que sucede dentro de los muros.

Estas condiciones marcan pautas para el trabajo de los profesores y directivos, y rebasan el ámbito académico para proyectarse hacia la atención de las necesidades sociales y culturales de cada comunidad.

Palabras claves: Contexto escolar, docentes de secundaria, condiciones sociales.

\section{Introducción}

El fenómeno educativo se concreta en los establecimientos escolares; no obstante, lo que ahí sucede no está al margen de los elementos que surgen de la esfera internacional, nacional, regional, estatal, municipal o regional.

Con este trabajo se intenta esbozar un análisis sobre las condiciones profesionales de los docentes y directivos que laboran en ocho escuelas secundarias que están situadas en el estado de Chihuahua, México, cuatro generales y cuatro técnicas todas ellas pertenecientes al subsistema federalizado.

El estudio se concluyó en el segundo semestre del ciclo escolar 2010-2011, y comprende escuelas ubicadas en diferentes regiones de la entidad: una de ellas en la Sierra Tarahumara, dos más están situadas en ciudades medias del noroeste y sur del estado, y cinco ubicadas en las dos poblaciones más grandes del estado. Tres de las escuelas se ubican en niveles socioecnómicos medio y alto, y se destacan académicamente; $y$ tres son de un nivel bajo, con situaciones problemáticas relacionadas con la pobreza y en cierta forma con la exclusión social; de modo que se recoge información de estos ocho contextos que reflejan una pluralidad de ambientes y necesidades sociales y educativas. 
Es desde luego indispensable situar los hechos de un plantel, de un docente y de los propios estudiantes en las peculiaridades de sus contextos para develar las tendencias que caracterizan a sus actores e identificar el énfasis con el que se orientan determinada políticas a nivel escuela o grupo, pero además para caracterizar el grado de complejidad en el que se desarrolla el hecho educativo y la multiplicidad de circunstancias, únicas e irrepetibles, que se manifiestan en el trabajo diario haciendo de la profesión docente y de la tarea encomendada un campo basto para su estudio.

Es proyecto fue desarrollado por un equipo de investigadores del Centro de Investigación y Docencia con el respaldo financiero del Fondo Mixto Conacyt - Gobierno del Estado de Chihuahua.

\section{Diseño metodológico}

En el siglo pasado, sobre todo en su segunda mitad a la fecha se ha desarrollado el enfoque interpretativo en la investigación social, remontando un prolongado debate epistemológico sobe el conocimiento del mundo natural que ha dominado con antelación y el reconocimiento de la especificidad del mundo social, y por lo tanto, de una forma distinta de explorarlo. A estas alturas del desarrollo del conocimiento queda claro que son dos mundos distintos pero que guardan una interrelación completa; que la naturaleza del objeto de estudio de cada uno de ellos requiere la utilización de enfoques, métodos y técnicas diferentes pero además, que cada uno de estos mundos tienen su propia identidad: el debate sobre lo objetivo y lo subjetivo está implicado al máximo, y los hechos sociales en particular no pueden ser estudiados bajo la óptica científico-positivista con la que se estudian los fenómenos de la naturaleza.

En particular, para esta investigación se asumió un enfoque interpretativo, a partir de registros de observación consignados en un diario de campo por un período de cuatro meses consecutivos, además de la realización de un conjunto de entrevistas individuales y la generación de varios grupos focales con los estudiantes.

Guzmán y Alvarado nos refieren a la posibilidad de generar teoría a partir de la información recaudada:

En el enfoque cualitativo el investigador plantea concepciones del conocimiento basadas en perspectivas constructivistas [...] El investigador obtiene datos abiertos, emergentes, con la intención principal de desarrollar teorías a partir de los datos; teorías útiles para interpretar o comprender fenómenos o procesos específicos (2009: 45).

Por otro lado, de acuerdo con Cresswell (citado por Luis Álvarez-Gayou, 2003) la etnografía es una descripción e interpretación de un grupo o de un sistema social o cultural.

Abundando en tal asunto,

El propósito de la investigación cualitativa desarrollada bajo la concepción constructivista es confiar tanto como sea posible en los puntos de vista de los participantes acerca del fenómeno que se estudia. Se intenta recuperar las construcciones de significado de los participantes acerca de un fenómeno o proceso; una construcción que se 
genera a partir de la interacción de las personas en un contexto específico y en un tiempo determinado (Guzmán y Alvarado, 2009: 47)

Según estos autores, y posicionados sobre los principios que subyacen al enfoque cualitativo, afirman que

los investigadores cualitativos reconocen que sus propias percepciones del mundo y sus valores influyen en su interpretación; por tanto, intentan atrapar el sentido o interpretar los significados que otros tienen acerca del mundo. A diferencia de la postura postpositivista, la investigación no se inicia con una teoría, sino que ésta surge inductivamente a partir del análisis de los datos (ibidem).

De modo que en este trabajo se ha incursionado en un acercamiento al objeto de estudio: las escuelas secundarias, los docentes, su desarrollo profesional y el contexto en que están insertas los planteles.

"La investigación cualitativa implica la utilización y recogida de una gran variedad de materiales -entrevista, experiencia personal, historia de vida, observaciones, textos históricos, imágenes, sonidos- que describen la rutina y las situaciones problemáticas y los significados en la vida de las personas" (Rodríguez Gómez, Gil Flores y García Jiménez, 1999: 32). Así, se presentan bajo una narrativa algunos elementos encontrados en el material empírico producto del trabajo de campo.

\section{Análisis de resultados}

El contexto en que laboran los docentes y directivos representa una fuente amplia de ele- mentos que matizan y hacen únicas e irrepetibles las condiciones laborales y profesionales de éstos.

Comprender el trabajo del maestro implica acercarse al lugar donde se desarrolla. Dicho trabajo se realiza bajo determinadas condiciones, que dependen tanto de la estructura y el contexto social del sistema educativo, como de las relaciones existentes dentro de cada escuela (Rockwell, 1985: 63).

Aún cuando en el nombramiento de un docente se especifican una serie de responsabilidades y funciones genéricas, éstas se incrementan sensiblemente dependiendo del lugar donde labora. Así, en un medio rural aislado los retos que se tienen que afrontar son cualitativamente distintos a los que enfrentan los equipos de un lugar suburbano o urbano, pero además, cada comunidad tiene sus peculiaridades, de tal forma que cada escuela y su contexto conforman un todo que definen la cultura institucional particular.

Se denomina contexto al conjunto de factores tanto externos, como el medio físico y social donde se inserta la escuela, las características y demandas del ambiente socio-económico de los educandos y sus familias, su radio de influencia y relación con otras instituciones, etc., las cuales impactan en la escuela y condicionan de alguna manera su gestión y el accionar del plantel docente (Cusel, Pechin y Alzamora, citados por Rockwell, 1985: 63).

Así, el contexto escolar se constituye por los diferentes elementos que se relacionan con la escuela y el proceso de enseñanza y aprendizaje que se realiza en ella. 
Por ejemplo, uno de los fenómenos más comunes en la actualidad es la violencia que está presente en el contexto general en que se ubican las escuelas y en los barrios o colonias en donde habitan una buena parte de los alumnos, como lo cita un informante de una escuela urbana: "el ambiente en la escuela es bueno aunque estamos rodeados de picaderos y de delincuencia organizada, usted ve la escuela y no hay pintas, está limpio y en orden" (Docente: 1:28; 290:292), y otro cuando nos comenta:

El fenómeno de la violencia ha obligado a tomar medidas que antes eran impensables. Se presentó el caso de una niña cuya familia fue asaltada $y$ denunciaron a los delincuentes, ahora están amenazados y tienen temor de traer a la niña a la escuela... me dicen ¿qué hacemos?... la alternativa es que trabaje en su casa, los profesores le dieron trabajo para que continúe la escuela a distancia (Director: 1:21; 177:183).

$\mathrm{Y}$ es que aún cuando la violencia está generalizada, en algunos lugares del estado el fenómeno es más acusado: "resulta imposible sustraerse de la influencia del medio social, la situación de inseguridad está presente en la escuela, un grupo de policías se dirigen a la dirección mientras los jóvenes van a la cafetería, también hay un equipo de una cadena de televisión haciendo un reportaje" (Observación: $1: 62 ; 589: 592)$.

Efectivamente, es difícil sustraerse de este ambiente ya que tan solo en el traslado de los estudiantes a la escuela o a la casa pueden ser víctimas de este fenómeno "los estudiantes tienen que pasar por los barrios. Por ejemplo de aquel lado del arroyo, si se pasan de un lado a otro los golpean, los persiguen. Eso causa conflicto" (Prefecto: 25:147; 576:578).
Pero además la violencia también está instalada en algunos hogares donde viven los alumnos: "sí, está muy marcado, tenemos varios casos de violencia intrafamiliar y eso se refleja aquí con los muchachos. Vemos regularmente que quien sufre violencia familiar en su casa, viene y aquí regularmente es violento" (Trabajadora Social: 25:149; 590:592).

La violencia también se genera dentro de la escuela sea porque el ambiente de conflicto de los barrios se filtra a los salones de clase o porque dentro del espacio escolar se generan motivos de disputa entre los alumnos. Es algo que se ha vuelto cotidiano y es parte del contexto: "Hemos tenido casos donde las señoras nos golpean alumnas fuera de la cerca de la escuela, y que vienen aquí a decir, y hasta llegan a las demandas entre ellas. Hay mucho chisme. Pleito por su hombre" (Trabajadora Social: 25:152; 598:601). Y esto se replica por ejemplo entre las alumnas ya que como dice un informante:

Las chicas riñen mucho por el afecto. Cuando una chica encuentra el afecto con otra amistad, con una compañera... de que somos amigas, o que tiene su parejita, y alguien que se lo quite, entra en conflicto esa necesidad de sentirse apreciada, porque aquí hay una incidencia muy alta de machismo (Docente: 28:108; 564:569).

Otro rasgo del contexto que se asocia en parte con esta tendencia violenta es la desintegración familiar:

En los primeros años empecé a notar que el papá era ya el abandonado y eso se lo digo de hace unos cuatro años, ya no eran las madres solteras, eran los papás solteros, la mamá se iba, se iba, dejaba a los hijos y sin piedad "y 
arréglatelas como puedas". Muchos, muchos casos, de hecho esa generación salió creo que el año... no sé si el año pasado o el antepasado, pero fueron grupos de ponerles tal vez no toda la atención pero sí lo que podías hacer por él, porque son grupos muy numerosos, y los primeros estaban marcados así (Docente: 6:41; 881:905).

$\mathrm{Y}$ es que la familia ha venido cambiando de tal forma que el modelo tradicional de familia nuclear está viviendo una crisis, como lo menciona un maestro: "yo creo que en México se gestaron cambios muy especiales a través del tipo de familias que tenemos, las familias han arrojado diferentes productos a la sociedad" (Docentes: 15:78; 1419:1421). O como lo menciona un alumno en un grupo focal:

I: - ¿cómo es la relación con tus papás? - Pues yo digo que va bien, como que mi padrastro y mi mamá se van a divorciar, y mi mamá me da mucha libertad, haga de cuenta que llego a mi casa hasta las ocho [...] Me paseo por el centro. [...] [Intervienen otros compañeros] -Es que como toca la guitarra se sube a los camiones a tocar y gana dinero. [...] - De hecho sí, también, pues es que ahí está la casa donde vivía la primera vez en mi vida, pues ahí me paso un rato porque ahí vive un señor con el que vivía mi mamá y pues ahí también es mi casa, ahí me la paso, hay equipo de batería, guitarra eléctrica y bajo, a ese señor lo considero como mi maestro de música. I: - ¿Y ese señor era otra pareja de tu mamá? $-_{¿} \mathrm{He}$ ? no, de pura amistad [...] Mi papá, mmh es que no sé cómo está el rollo, trabaja en un taller, y luego es ingeniero de una compañía de gas, no sé dónde. I: $-i Y$ no lo ves? -Sí, es que nos da dinero cada semana (Alumnos: $24: 11 ; 267: 292)$.

Diferentes versiones de los entrevistados en este estudio señalan el impacto de la desintegración familiar en el ambiente escolar y la vida de los alumnos ya que con frecuencia existe:

Violencia en todos los niveles, desintegración familiar al por mayor, inclusive hay estudios aquí de la trabajadora social que ella se ha abocado a hacer en donde tiene datos, que es difícil contar con familias completas, o conviven con padrastros o madrastras o con los abuelos o con padres solteros (Prefecto: $25: 186 ; 973: 979$ ).

Así es como los docentes de manera inevitable tienen que enfrentar problemas que van más allá del trabajo académico, el contexto que determina infinidad de variantes con las que tienen que tratar en su desempeño diario.

La crisis que se vive también en el empleo deja sus marcas y representa un peso importante en las condiciones de vida de las familias de los estudiantes y por consecuencia tienen su efecto en la dinámica educativa:

Sí, tenemos muchísimos alumnos que se van, población flotante, de trabajo también, porque se van a la ciudad de Chihuahua, a Cd. Juárez. Creo que este año es donde yo he visto menos de que se vayan, porque en otros años, te estoy hablando de que cada año se pierde por diversas situaciones un grupo [...] entre los que se van y llegan, pero antes, yo sí veía todavía el año pasado de que se iban muchísimos [...] como que a lo mejor la cuestión de la seguridad, pues se están yendo menos, verdad, pero pues sí, los problemas de falta de trabajo aquí siguen siendo igual (Docente: $36: 373 ; 4020: 4035)$. 
Pues es un nivel socioeconómico bajo, en donde hay muchos muchachos con papás desempleados, tenemos muchos alumnos que entran en cierto tiempo y que emigran porque tenían casa de renta. Es muy difícil porque los ve uno y que sabe que a veces no tienen ni para almorzar. A algunos les hemos conseguido desayunos escolares. Sí, es un nivel socioeconómico muy difícil, donde tenemos indígenas tarahumaras y del sur del país (Director: 29:149; 895:901).

Nosotros aquí tenemos un mosaico de culturas, gente que viene de todas las partes de la república, entonces hay momentos críticos o específicos, por ejemplo cuando hay crisis de empleo en la maquila se van a su población de origen y nosotros perdemos alumnos (Director: 5:60; 1066:1090).

La evolución o envejecimiento mismo de las colonias afecta de manera importante a las escuelas, cuando una colonia está en desarrollo y auge, entonces la afluencia de alumnos es muy marcada, pero conforme pasa el tiempo, las personas se van a vivir a otros lados y se reduce la demanda de estudiantes. Esto genera que algunas escuelas tengan que entablar estrategias para ganar estudiantes y sostener la matrícula. Así, los docentes y directivos tienen una nueva línea de acción que hace cambios en sus condiciones de trabajo y la diversificación de sus tareas:

Yo ingresé a esta escuela cuando eran dos turnos, teníamos del grupo "A" al "G" llenísimos. Claro en todas las escuelas ha disminuido la matrícula de alumnos y estamos en una zona de influencia muy difícil porque enfrente tenemos una secundaria que ya con el hecho de que como padre de familia no pase tu hijo el periférico, pues lo dejas allá, primero. Al lado no tenemos colonias más que una, pero esos niños estudian en la escuela que está enseguida de la secundaria y lógico, se van para allá. [...] Son colonias que están pues retiradas de la secundaria, entonces tuvimos un tiempo en que esas colonias pues tenían muchísimos niños. [...] se le ocurrió la estrategia de que vamos a la casa, vamos a hablarles por teléfono, vamos a invitarlos y [...] aumentó la matrícula (Docente: 36:371; 3983:4017).

También en este ambiente que rodea a las escuelas, se encuentra sobre todo en las ciudades, posturas de padres de familia bastante agresivas y demandantes:

"Es buena, también hemos tenido problemas con profes. Han venido padres de familia enojados a querer golpear a profes; hemos hablado con ellos y les decimos, bueno, nosotros nos hacemos cargo de la situación" (Director: 29:259; 3023:3025).

"Me desagrada la gente cuando traen los conflictos aquí. De los padres de familia que son muy violentos, porque soy la que trabajo directamente" (Trabajadora Social: 25:160; 665:666).

\section{A manera de conclusión}

Y así, de diferentes formas, las evidencias empíricas nos dan algunas pistas acerca de la manera en que el contexto modela las circunstancias particulares para cada escuela y para cada alumno y por lo tanto para cada docente. Estas diferencias se reflejan en la dificultad para separar lo educativo del contexto social, 
por la cantidad y diversidad de problemas que se deben atender de manera simultánea, por las resistencias que se cruzan para avanzar en los aprendizajes, por las condiciones de apoyo o deficiencias para desarrollar su tarea, por las posibilidades de trabajar en colectivo o asumir de forma aislada los diferentes problemas que se encuentran a diario. Estas condiciones particulares hacen que la función docente y directiva no pueda ser mecanicista ni ciega, sino que tiene que verse desde una visión amplia y generar las intervenciones de forma inteligente, ajustándose a las circunstancias tan variadas.

\section{Bibliografía}

Álvarez-Gayou Jurgenson, Juan Luis (2003), Cómo hacer investigación cualitativa: fundamentos y metodología, Editorial Paidós, México, Serie Paidós Educador 169.

Guzmán Arredondo Arturo y Alvarado Cabral José Jesús (2009), Fases y operaciones metodológicas en la investigación educativa, Asociación de Investigadores en Ciencias de la Educación, COCYIED, ICED, Durango, Dgo. México.

Rockwell Elsie (1985) Ser Maestro, estudios sobre el trabajo docente. Antología. Los contextos del trabajo docente p. 63, Edición: Consejo Nacional de Fomento Educativo, Distrito Federal, México: Ediciones El Caballito

Rodríguez Gómez Gregorio, Gil Flores Javier y García Jiménez Eduardo (1999), Metodología de la investigación Cualitativa, Ediciones Aljibe, segunda edición. Málaga España.

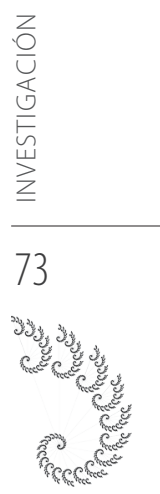


